\title{
CERCAMENTOS NA BAIXADA MARANHENSE: IMPLICAÇÕES DE TAIS PRÁTICAS NA COMUNIDADE QUILOMBOLA DE CAMAPUTIUA EM CAJARI- MARANHÃO
}

Vanessa Cristina Ramos Fonsêca da Silva ${ }^{1}$

\section{RESUMO}

O presente artigo analisa a situação dos cercamentos na Baixada Maranhense e suas implicações jurídicas e ambientais na Comunidade Quilombola de Camaputiua, localizada em CajariMaranhão. Objetivou-se indicar a existência das cercas nos campos na referida área, e analisar como elas fomentam a existência de conflitos agrários e socioambientais na região, através dos métodos indutivo e históricos, por meio da realização de entrevistas semiestruturadas, estudo bibliográfico e documental.

Palavras-Chave: Cercamentos. Direito Agrário. Propriedade. Baixada Maranhense. Comunidade Quilombola de Camaputiua.

ENCLOSURES IN BAIXADA MARANHENSE: implications of such practices in the Quilombola Community of Camaputiua in Cajari-Maranhão

\section{ABSTRACT}

This article analyzes the situation of enclosures in the Baixada Maranhense and its legal and environmental implications in the Quilombola Community of Camaputiua, located in CajariMaranhão. The objective was to indicate the existence of enclosures in that area, and to analyze how they foster the existence of agrarian and socio-environmental conflicts in the region, through inductive and historical methods, through semi-structured interviews, bibliographic and documentary studies.

Keywords: Enclosures. Agrarian Law. Property. Baixada Maranhense. Quilombola Community of Camaputiua.

\section{Introdução}

O presente trabalho tem como objetivo estudar a situação dos cercamentos dos campos naturais inundáveis na comunidade quilombola de Camaputiua, localizada no município de Cajari-Maranhão, na Área de Proteção Ambiental da Baixada Maranhense.

Objetivou-se indicar a existência das cercas nos campos na referida área, e analisar como elas fomentam a existência de conflitos agrários e socioambientais na região, através dos métodos indutivo e históricos, por meio da realização de entrevistas semiestruturadas, estudo

\footnotetext{
${ }^{1}$ Advogada. Bacharela em Direito pela Universidade Federal do Maranhão. Especialista em Direito Constitucional pela Universidade Estácio de Sá. Mestra em Cartografia Social e Política da Amazônia pela Universidade Estadual do Maranhão. Pesquisadora do Núcleo de Estudos Afro-brasileiros e Indígenas (NEABI) do Instituto Federal de Educação, Ciência e Tecnologia do Maranhão (IFMA)-Campus Maracanã. E-mail: vanessa.rfonseca@hotmail.com . 
bibliográfico e documental.

“Enclosure” é a expressão inglesa que significa o cercamento. A partir do século XVII, na Inglaterra, passou a designar o processo de eliminação dos campos abertos ou pastos comuns mediante o cercamento de terras, que passaram a constituir propriedade privada dos "landlords" (senhores de terras).

O processo de cercamento provocou a substituição de lavouras por pastagens para a produção de lã (matéria-prima por excelência da florescente indústria têxtil inglesa), causando a ruína dos camponeses que antes habitavam essas terras e sua migração maciça para as cidades (SANDRONI, 1999, p. 206).

Os primeiros cercamentos na Inglaterra recorreram ao conceito da "melhoria" de Locke (1952, p. 37) para justificar suas ações. As formas contemporâneas de desapropriação costumam recorrer à linguagem derivativa do "desenvolvimento". Isso depende fundamentalmente dos propósitos econômicos usados para justificar a desapropriação e seus beneficiários. Tudo indica, por exemplo, que os camponeses ingleses rejeitaram os argumentos morais e jurídicos usados para justificar os cercamentos (THOMPSON, 1998), que se apoiavam naquilo que E. P. Thompson chama de "a ascendência da força". No "Ocidente", o consenso foi facilitado pelo fato de que os cercamentos em grande escala ocorreram antes da instituição da democracia eleitoral - ou se voltavam contra populações sem direito a voto (BANNER, 2005).

A partir do século XV, parte da nobreza inglesa (gentry) iniciou a apropriação das terras da população pobre camponesa.

$\mathrm{Na}$ Inglaterra a expansão do capitalismo iniciou-se com a edição de Leis de cercamento através das quais passou-se a crescente privatização de terras de uso comum (open fields) que foram expropriadas dos camponeses e passaram a ser cercadas e exploradas por poderosos senhores locais, que por sua vez passaram à condição de proprietários.

Naquele contexto a partir do século XV, uso das terras que antes era exercido de forma comunal pelos camponeses, que gozavam de acesso aos recursos para pequena produção e subsistência, passaram a ser campos fechados. No século XVII, na Inglaterra, mediante a prática do cercamento as terras foram definitivamente transformadas em bens privados destruindo os direitos comuns.

Dentre as consequências a terra passou a ser mercadoria, sendo então propriedade privada, passando a excluir dos camponeses dos meios de sustento. 
Os camponeses ao serem expropriados do uso da terra e seus recursos não tiveram alternativa senão vender sua força de trabalho e buscar na cidade uma nova forma de subsistência: o trabalho como mão de obra barata nas fábricas contribuindo para a formação da classe operária.

A tendência mundial ao desaparecimento de sistemas comunais, iniciada no século XIII com os "enclosures" ingleses, coincide com o avanço da mercantilização da terra e do trabalho (POLANYI, 2000).

Ost (1997, p. 57) recorda que, por muito tempo o direito consuetudinário controlou o uso da natureza na Europa, instituindo servidões para garantir a complementariedade dos fundos e a interdependência dos meios de utilização dos recursos naturais. Eram os usos e costumes, particularmente numerosos antes de 1789, que limitavam o direito de cada categoria de usuário.

\section{Cercamentos na Baixada Maranhense}

$\mathrm{Na}$ Amazônia brasileira, em terras maranhenses e nos tempos atuais, verifica-se que a estrutura fundiária mantém uma relação de profunda semelhança com a situação da Inglaterra pré-capitalista, como se houvesse uma linha de continuidade no tocante ao aspecto do cercamento dos campos inundáveis.

Nesse sentido, Almeida e Mourão (2017, p. 91) afirmam que, no Maranhão, especialmente na região dos campos e lagos, "o cercamento das terras com arames farpados robustos, reforçados, evidencia o propósito de uma apropriação privada e definitiva dos recursos naturais". Os autores enfatizam a riqueza da biodiversidade da região, com vários rios e lagos, destacando a existência de babaçuais em suas reentrâncias.

Utilizando-se de novos arranjos estas práticas são reeditadas, dando seguimento também ao êxodo rural e à força de trabalho que muitas vezes direciona-se às indignas condições de trabalho análogo à escravidão.

O processo de cercamento de terras, ou seja, de privatização de terras inclusive da União e do Estado pelos latifundiários resultou na expulsão dos trabalhadores das áreas em que plantavam suas roças, fazendo cultivos que garantiam a sua sobrevivência, como a mandioca, o milho, o feijão. Essas áreas foram sendo transformadas em pastagens e as famílias dos trabalhadores do campo foram sendo obrigadas a dedicarem-se à prática do extrativismo, como única forma de garantir a sua sobrevivência.

A terra é a variável constante que tanto acolhe como expulsa os trabalhadores, tornando-os reféns dos processos de cercamento que se reproduzem, sob novas modalidades de 
apropriação dos territórios pelos setores do agronegócio, transformando-os em novas gerações de trabalhadores sem-terra, sem teto. Tornam-se portanto, integrantes dos contingentes que vendem a sua força de trabalho para a exploração análoga a que se praticou com os escravos, quando não são exterminados, como ocorreu em vários estados brasileiros, incluindo o Maranhão, em que a luta pela terra transformou-se numa guerra entre desiguais.

A Área de Proteção Ambiental da Baixada Maranhense ${ }^{2}$ constitui uma ampla região marcada pela diversidade de ricos ecossistemas, tais como rios, lagos estuários e áreas alagáveis. Fazendo parte da Amazônia Legal Brasileira ${ }^{3}$, é formada pelas bacias hidrográficas dos rios Mearim, Pindaré, Grajaú, Pericumã, Turiaçu e outros menores. Estes rios transbordam anualmente e suas águas inundam as planícies da região.

Figura 1 - Mapa da APA da Baixada Maranhense

${ }^{2}$ A Área de Proteção Ambiental da Baixada Maranhense está localizada nos municípios de Anajatuba, Arari, Bequimão, Cajapió, Lago Verde, Matinha, Mirinzal, Monção, Olho D’Água das Cunhãs, Palmeirândia, Penalva, Peri-Mirim, Pinheiro, Pindaré-Mirim, Pio XII, Santa Helena, São Bento, São João Batista, São Mateus, São Vicente de Férrer, Viana, Vitória do Mearim, e na Ilha dos Caranguejos, em uma área de aproximadamente de 1,8 milhão de hectares, que vai da região continental do oeste a sudeste da Baía de São Marcos.

${ }^{3}$ Conforme a Lei Complementar $n^{\circ} 124$, de 3 de janeiro de 2007, que institui, na forma do art. 43 da Constituição Federal, a Superintendência do Desenvolvimento da Amazônia - SUDAM. 


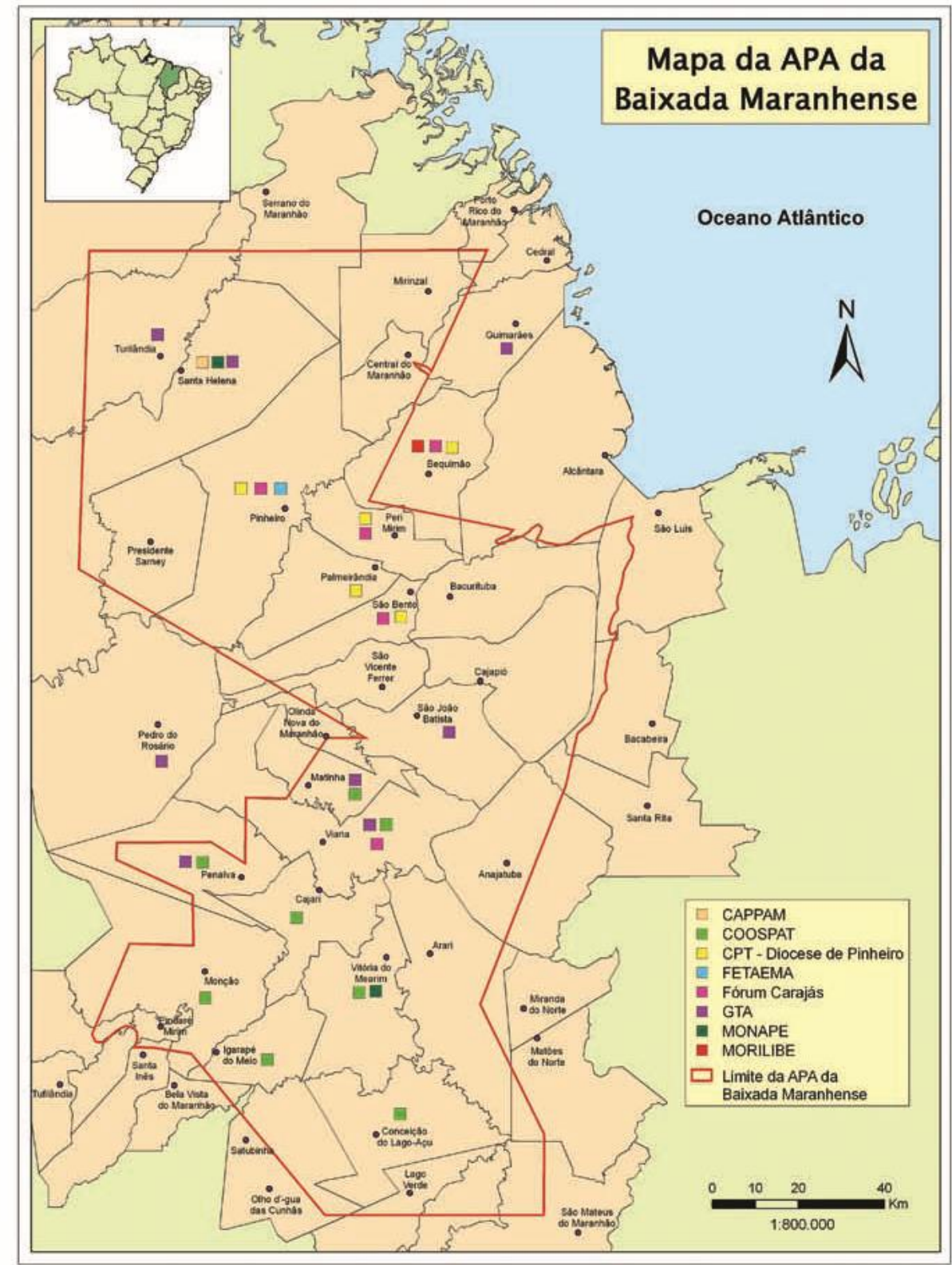

Fonte: MINISTÉRIO DO MEIO AMBIENTE (2020).

A APA da Baixada Maranhense é considerada uma zona úmida de importância internacional pela Convenção de Zonas Úmidas de Importância Internacional (Convenção de RAMSAR), que está em vigor desde 21 de dezembro de 1975. Ela foi aprovada pelo Congresso Nacional em 16 de junho de 1992 (Decreto Legislativo no 33), ratificada em 1993 e incorporada plenamente ao ordenamento jurídico brasileiro através do Decreto $\mathrm{n}^{\circ}$ 1.905/96.

Carvalho Neta et al (2015, p. 55) destacam que a importância ecológica da Baixada decorre da presença de planícies inundáveis do período chuvoso, formando um dos maiores sistemas lacustres brasileiros. Além disso, os rios e lagos têm grande importância ecológica e 
socioeconômica, o que tem potencializado diversas atividades como a pecuária, a pesca e a agricultura, gerando conflitos sociais e devastação ambiental. Contudo, a exploração desordenada dos lagos, dos solos de várzea e a da vegetação vêm provocando impactos ambientais na região.

Ademais, a referida APA ainda não elegeu seu Conselho Consultivo e nem elaborou o seu plano de manejo, o que tem fomentado o crescimento desordenado da região e dificultado a sua preservação.

A região fica seis meses seca e seis meses alagada. $\mathrm{O}$ pico das enchentes ocorre em abril e maio, enquanto que o nível mínimo d’água se registra em novembro e dezembro. $\mathrm{Na}$ estação chuvosa, quando os rios e lagos transbordam, os campos são inundados e transformados em extensos lagos rasos. Parte das águas é devolvida aos rios quando seus níveis baixam.

Figura 2 - Trecho de Camaputiua no período de chuvas (fev/2019) e no período de seca (nov/2018)

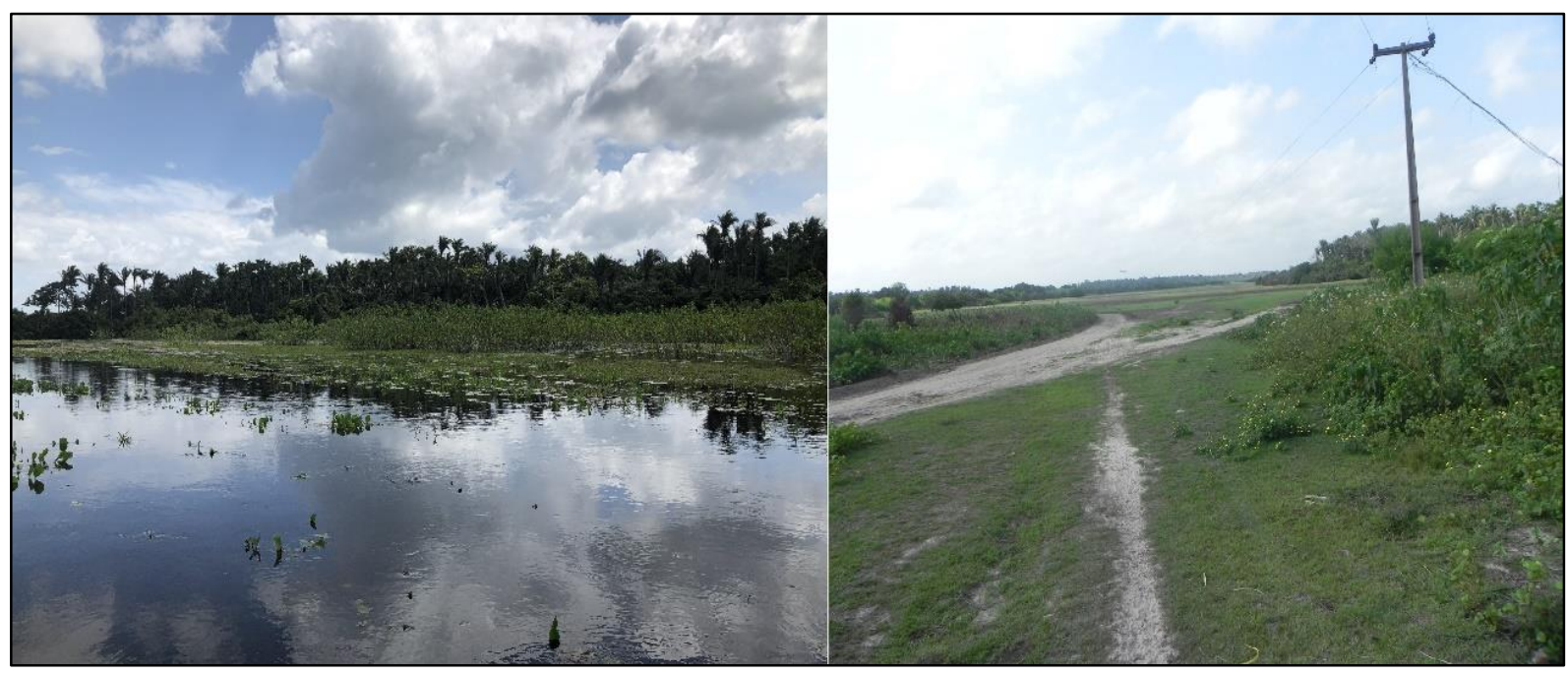

Fonte: Autora (2018/2019)

O Decreto Estadual n 11.900 , de 11 de junho de 1991, criou a Área de Proteção Ambiental (APA) da Baixada Maranhense com o objetivo de disciplinar o uso e a ocupação do solo, a exploração dos recursos naturais, as atividades de pesca e caça predatórias, a criação de gado bubalino, a integridade biológica das espécies, os padrões de qualidade da água e proteção aos refúgios das aves migratórias.

Vários campos cercados estão em área de proteção ambiental da Baixada Maranhense, portanto estão submetidos a regras rígidas de uso, conservação e controle, e deveriam permanecer sob proteção do Estado. 
Apesar de a norma Estadual prever a retirada das cercas e dos búfalos das terras públicas e a preservação dos campos naturais, esse é um problema que ocasionou sérios conflitos nas décadas anteriores e que ainda continua presente na região. Ademais, o Código de Águas (Decreto Federal 24.643/1934- arts. $1^{\circ}, 2^{\circ}, 5^{\circ}, 53,54$ e 55) e a Política Nacional de Recursos Hídricos (Lei 9.433/1997-art. 1º, I) classificam a água como bem de domínio público. Sem contar que o cercamento de áreas públicas é considerado crime de acordo com a Lei $\mathrm{n}^{\circ}$ 4947/1966 4 e de acordo com o Código Penal $^{5}$ (no caso em que a eletrificação de cercas configura o crime de expor a perigo a vida ou saúde de outrem).

Segundo Almeida (1992, p. 12), as terras comunais constituem uma antiga instituição, que se fundamentou historicamente ao lado dos domínios do Estado e das propriedades da Igreja. As chapadas do sul do Maranhão, os campos da Baixada Maranhense e o Baixo Parnaíba mantém-se ainda hoje como áreas de pastagens comunais.

A utilização de cercas em áreas inundáveis, sobretudo as cercas com eletrificação, são de uso proibido conforme o novo código florestal. Através da lei federal $\mathrm{n}^{\circ} 12.651$ de 25 de maio de 2012, fica previsto que, em áreas de preservação permanente, a manutenção do perímetro mínimo de proteção seja de pelo menos 30 metros.

Entretanto, esses cercamentos são muito presentes em Camaputiua. Ednaldo Padilha, conhecido como Cabeça (PADILHA, 2016, p. 82) relata que:

\begin{abstract}
A questão das cercas é como a gente pode perceber que em nossas visitas, a gente já passou a ser vítima. No entanto no verão tem o crime já do meio ambiente, a grande tirada de estacas que devasta muito os araribais das áreas de mananciais da beira dos rios e também a questão da privatização que o campo como é um campo público, na verdade ele não é público, ele fica privatizado, fica para poucos e muitos ficam sem ter acesso a esse campo que seria para todos, seria de uso comum e até o impedimento da retirada do sustento da família, do pescado, até mesmo de botar suas pequenas lavouras nos campos e também seus pequenos animais, suas pequenas criações, como pato, porco. As pessoas ficam impedidas, toda a comunidade que está à margem, a beira daqueles campos privatizados eles sofrem muitas dificuldades, porque não tem a liberdade de criar, de ir e vir, então a situação é muito difícil e como a gente viu a questão do búfalo devastam muito os campos.
\end{abstract}

Segundo Cabeça (Ednaldo Padilha), há várias atividades de uso comum em Camaputiua. No inverno (período chuvoso) há o predomínio da pesca. No verão (período seco) prevalece a plantação de mandioca. Além dessas atividades, há também a coleta e quebra de coco babaçu, que é realizada tanto no inverno quanto no verão. O babaçu tem grande relevância

\footnotetext{
${ }^{4}$ Art. 20. Invadir, com intenção de ocupá-las, terras da União, dos Estados e do Municípios: Pena: Detenção de 6 meses a 3 anos.

${ }^{5}$ Art. 132 - Expor a vida ou a saúde de outrem a perigo direto e iminente: Pena - detenção, de três meses a um ano, se o fato não constitui crime mais grave. 
na economia de Camaputiua, onde há uma cooperativa para o seu processamento. Diante disso, há o destaque para a liderança de dona Maria Antônia, mãe de Cabeça (Ednaldo Padilha) e liderança quilombola e do Movimento Interestadual de Quebradeiras de Coco Babaçu (MIQCB).

Dorival Santos (2015, p. 104) relata que os cercamentos nos campos públicos inundáveis do Território Quilombola de Camaputiua iniciaram a partir da década de 1990, depois do início da criação de gado bubalino, quando houve a privatização da área pelos fazendeiros que querem demonstrar o controle da terra.

Logo, nota-se o processo da privatização do público, sendo que os campos inundáveis são públicos e de uso comum. Segundo Dourado (2014, p. 162), no sistema de uso comum "nenhuma pessoa detém o controle exclusivo do uso e da disposição dos recursos básicos para a comunidade. A gestão dos recursos naturais é feita pelas próprias comunidades por meio de normas explícitas ou de acordos tácitos". Com os cercamentos, os quilombolas de Camaputiua se veem impedidos de usufruírem dos recursos naturais, que é fonte de sustento e de renda para eles.

Andréa de Sá (2010, p. 102) ${ }^{6}$ explica que, no território de uso comum, “o público se refere ao comunitário, ao espaço que se organiza e funda um modo de produzir a vida em espaços comuns: no criadouro dos animais, na área de plantação, nos recantos do religioso e nas praças das festas". Tais características do uso comum são muito presentes em Camaputiua e encontram muitos entraves mediante o sistema de privatização dos espaços de uso comum.

Garret Hardin foi um defensor da privatização dos espaços de uso comum. Dourado (2014, p. 163) reflete que sua interpretação em seu ensaio denominado "A tragédia dos comuns" foi equivocada, à medida que ele defendia o fim dos regimes de uso comum dos recursos naturais, argumentando que "uma vez que o livre acesso e a demanda irrestrita dos usuários, motivados pelos seus próprios interesses, acabariam por esgotá-lo”. Para Hardin, a conservação dos bens públicos só seria efetivo com a individualização da propriedade.

François Ost (1997, p. 157) menciona que esse pensamento assimila a ideia de

\footnotetext{
6 “Se o público é o comunitário, o privado é o criado no espaço da casa, na horta, no galinheiro do quintal, nas mudas das flores do jardim e na manutenção do material de trabalho, patrimônio familiar. Nesse modelo de uso territorial corresponde também um direito do acordo comunitário e das práticas de solução de conflitos emergente dos sujeitos, viventes e criadores deste território, que pode ser reconstituído a cada conflito, partindo dos próprios sujeitos as soluções, os abrigos e as punições. Neste caso, a regulação prevê as lutas internas, as contradições e os embates, nas quais os poderes espalhados na teia social se apresentam e se confrontam, recriando direitos exercidos comunitariamente, já que nascem submersos em uma mesma condição de vida e existência material" (SÁ, 2010, p. 102).
} 
privatizar o meio ambiente, colocando no mercado os bens naturais o mais rapidamente possível, pois essa seria a melhor maneira de preservá-los.

Contudo, esse posicionamento, inclusive, já foi cientificamente comprovado de que é equivocado, pois, o novo Relatório do Painel Intergovernamental sobre Mudanças Climáticas (IPCC) identifica conhecimentos e práticas indígenas como importantes elementos para prevenção dos efeitos das mudanças climáticas. O Painel chegou à conclusão de que "o fortalecimento da segurança da posse de terra das comunidades indígenas pode levar a um melhor manejo florestal, especialmente ao capacitá-los a excluir atores externos que buscam se apropriar de suas terras e recursos" (GIBBS; SEYMOUR, 2019).

Nessa ótica, Cabeça (PADILHA, 2019) afirma que: "Hoje quem tá salvando o país ainda é a resistência dos quilombolas e dos indígenas. É resistência mesmo. Não tá lá porque é bonzinho, mas porque dá a vida por aquilo".

Isso se dá pela relação que os quilombolas têm com a terra, com relação de pertencimento e laços culturais. Seguindo essa linha de entendimento, Haesbaert (1994, p. 210) afirma que a territorialidade tem uma natureza política, econômica e cultural, pois está intimamente ligada ao modo como as pessoas utilizam a terra, como elas próprias se organizam no espaço e como elas dão significado ao lugar.

Os modos de vida de povos e comunidades tradicionais, no que se refere ao uso da terra, se assemelham ao sistema pré-capitalista, pois os mercados são acessórios da vida econômica, e não a motivação de uma sociedade de mercado. Logo, predominam-se práticas de uso comum dos recursos naturais e entendendo-se a terra como bem comum, e não como simples mercadoria (CASTRO, 1998, p. 10).

Castro (1998, p. 13) destaca que os usos da terra e de seus recursos fazem parte de modos de vida. Logo, os povos e comunidades tradicionais encontram, nesse território, suas condições de reprodução física e cultural.

Para Almeida (2009, p. 66), no sistema de uso comum nenhuma pessoa detém o controle exclusivo do uso e dos recursos elementares para a comunidade. O uso dos recursos naturais é gerido pelas próprias comunidades através de regras explícitas ou de acordos tácitos. Alguns recursos têm acesso livre com controle coletivo, sendo sujeitos a disposições comunitárias que delimitem o seu uso.

Assim, Leroy (2011, p. 10) afirma que os bens de uso comum não são totalmente de livre acesso, mas “algo socialmente construído, fruto da história da humanidade".

Portanto, os cercamentos restringem o uso a esses recursos. Além de causarem uma 
série de problemas socioambientais tanto na época seca quanto no inverno. Na época seca há a predominância do viés privatista do público, com restrição ao acesso a recursos extrativistas, como o coco babaçu ${ }^{7}$.

As cercas, em especial as eletrocutadas, podem causar acidentes graves e até mesmo a morte. Há um registro de ocorrência (em anexo) de uma quebradeira de coco babaçu que sofreu um acidente e ficou com o corpo cheio de hematomas.

Figura 3 - Campos inundáveis no período de inverno e estacas de cercas- fev. 2019.

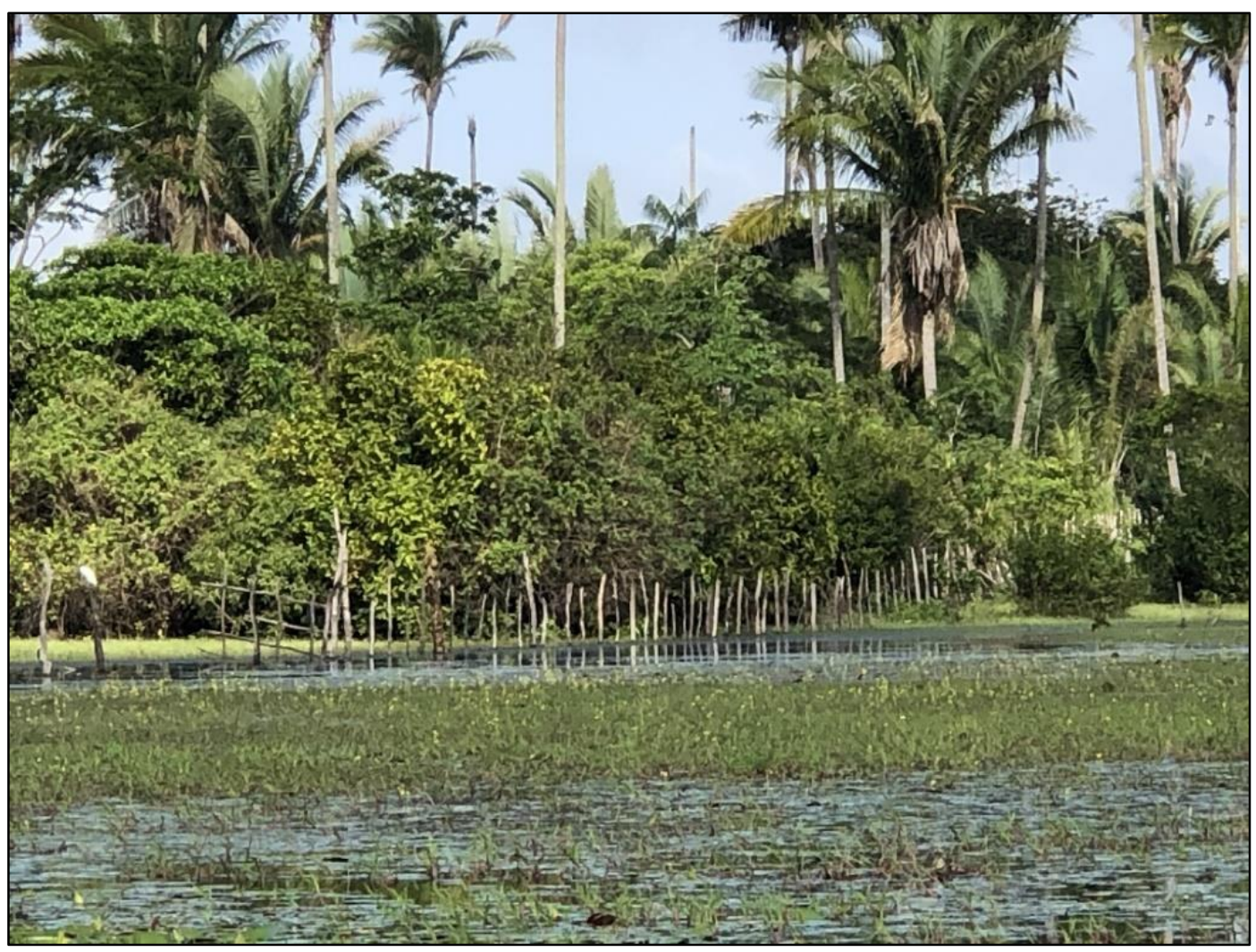

Fonte: Autora (2019)

Já na época chuvosa há o risco de acidentes de navegação por conta das estacas, que são as estruturas de madeira das cercas. Ademais, elas impedem o acesso dos quilombolas aos recursos pesqueiros em determinadas áreas dos campos, o que prejudica o sustento dos

\footnotetext{
${ }^{7}$ A Constituição Estadual do Maranhão de 1990, dispõe em seus Art. 195 e 196 que: "São inalienáveis os campos inundáveis das terras públicas e devolutas de domínio do Estado, e o seu uso será disciplinado por lei, que assegurará as formas comunais de sua utilização e a preservação do meio ambiente". Art. 196: "Os babaçuais serão utilizados na forma da lei, dentro de condições que assegurem a sua preservação natural e do meio ambiente, e como fonte de renda do trabalhador rural. Parágrafo Único - Nas terras públicas e devolutas do Estado assegurar-se-a exploração dos babaçuais a regime de economia familiar e comunitária".
} 
quilombolas, por interferir diretamente na renda familiar.

Figura 4 - Campos inundáveis no período de inverno e estacas de cercas- fev. 2019

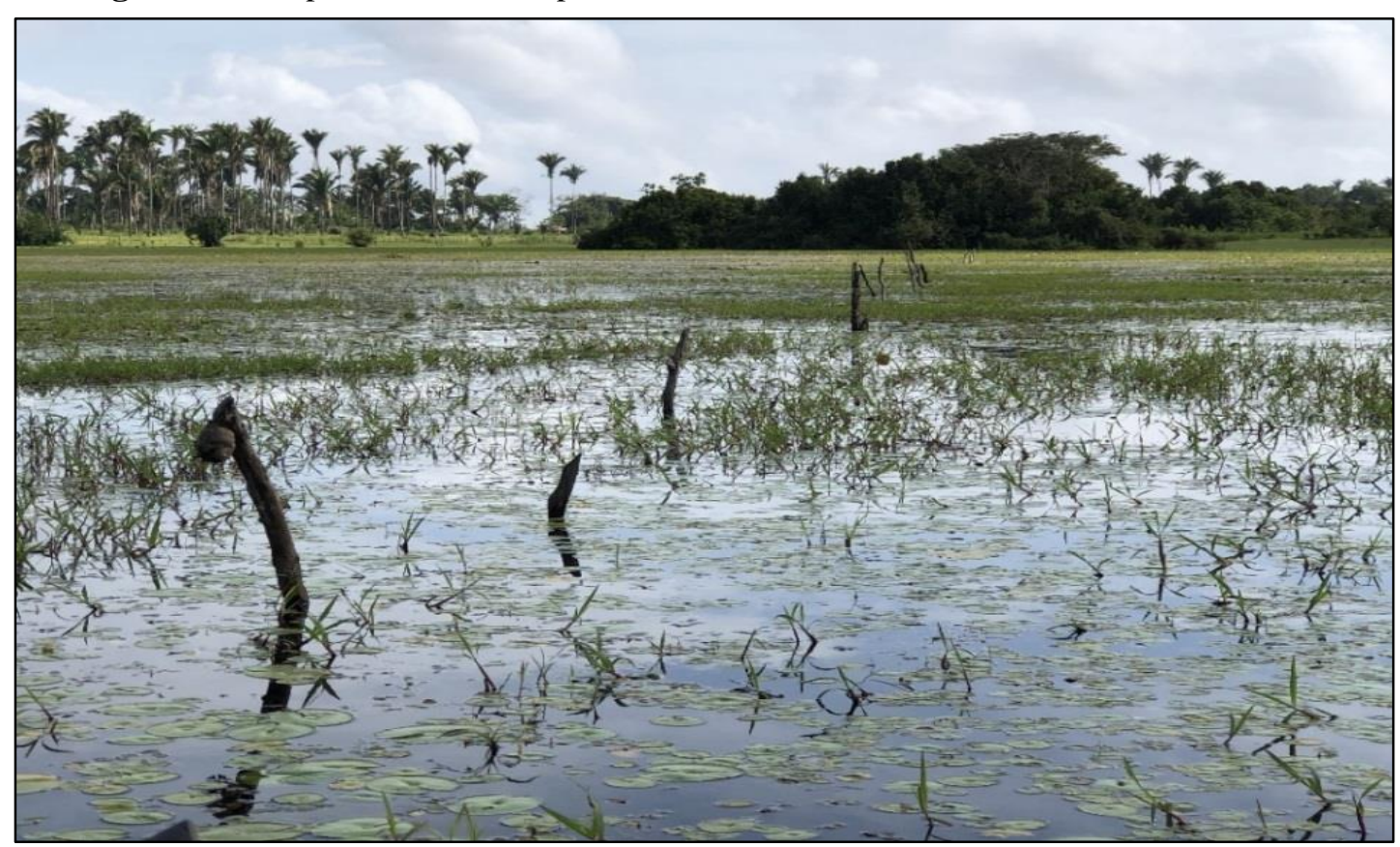

Fonte: Autora (2019)

Figura 5 - Estaca de cerca denominada "mourão", que pode ocasionar acidentes marítimos /fev. 2019

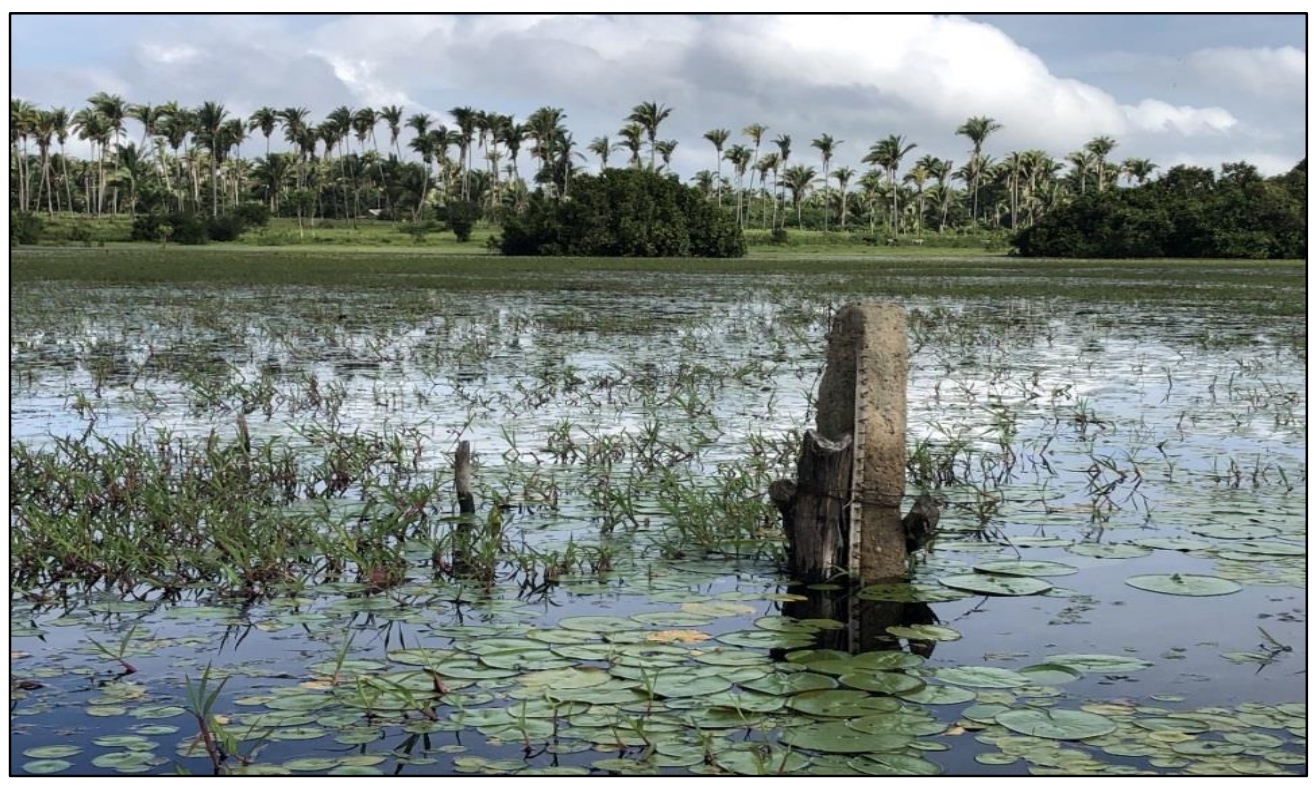

Fonte: Autora (2019) 
Ednaldo Padilha, conhecido como Cabeça, (PADILHA, 2019) relatou que, em um dos acidentes, um quilombola perdeu muitos dos seus bens, pois, ao bater em um mourão a canoa virou:

\begin{abstract}
Aqui teve um rapaz que se alagou. Ele vinha com a rabeta, a canoa foi pra cima de uma estaca dessas e a canoa virou. Ele vinha com uma muda de casa, com fogão, bujão... virou aqui, em cima da correnteza, aqui muito fundo e perdeu tudo. Não perdeu a vida porque já vinha outro e socorreu ele. Só foi achar as coisas no verão e não prestava mais. Essas estacas aqui acho que ficam a um metro abaixo da água. Aí o perigo é quando tá enchendo e quando tá secando. Estaca... a canoa pode bater. No inverno eles tiram o arame mas ficam as estacas.
\end{abstract}

Mesmo com a proibição de construção de cercas nos campos públicos inundáveis, os quilombolas foram processados judicialmente pelos fazendeiros (Processo 6/2001- 2a Vara da Comarca de Viana). Eles foram absolvidos em primeiro grau com a fundamentação de que a escritura dos fazendeiros não era legítima.

Os fazendeiros recorreram ao Tribunal de Justiça e venceram a demanda, pois o Tribunal permitiu que os fazendeiros cercassem a área, desde que deixassem uma passagem para os quilombolas. Além disso, os quilombolas ainda foram condenados a restituir o valor pecuniário que havia sido gasto para se levantarem as cercas.

Sobre isso, Santos (2015, p. 107) reporta as palavras de Cabeça:

\begin{abstract}
Aí a gente foi e tirou as cercas, ai depois eles conseguiram uma reintegração de posse, e aonde a gente questionava que a terra onde eles estavam cercando era de Camaputiua, e a escritura de Camaputiua que nossos antepassados compraram é de 1932, e ele tinha comprado em 1999, conseguir uma escritura de 1999 e o juiz consegui uma liminar pra ele de reintegração de posse, que estava dentro da área de Camaputiua, não tinha cadeia dominial, onde ele ganhou a questão, onde hoje ainda está lá essa cerca e a gente vê, ai um grupo de pessoas que queria nos prejudicar por questões políticas foram, mandaram alguém cortar as cercas, e a gente foi responder processo e hoje a gente tem uma condenação, saiu em 2011, saiu a nossa condenação por turbação, foi o tribunal de São Luís, que já decidiu, essa decisão de 37 mil reais por turbação da área.
\end{abstract}

Diante dessas violações da legislação com a construção de cercas pelos fazendeiros, os quilombolas realizaram um abaixo-assinado mediante auxílio da Defensoria Pública do Estado do Maranhão com o fito de solicitar a retirada das cercas eletrificadas (em anexo). Eles alegaram que a eletrificação das cercas limita o trânsito das pessoas e dos animais, o que estava causando morte de animais e acidentes com pessoas. Foram realizadas incursões para verificar a situação, mas o problema ainda persiste.

A incursão mais recente foi a realização da denominada "Operação Baixada Livre"

Rev. de Direito Agrário e Agroambiental| e-ISSN: 2526-0081| Evento Virtual| v. 6 | n. 1 | p. 40-56 | Jan/Jun. 2020 
promovida em 2017 pelo Governo do Estado do Maranhão, mediante a participação das Secretarias de Meio Ambiente, Direitos Humanos e Participação Popular, Igualdade Racial, Agricultura Familiar, ITERMA, Polícia Militar, Polícia Civil, Bombeiros, Batalhão de Polícia Ambiental e apoio da CEMAR.

Segundo o Relatório de Atividades da Operação na cidade de Matinha, ela teve como objetivo retirar as cercas dos campos públicos inundáveis e efetivar a legislação ambiental e agrária, de forma a "preservar a Baixada Maranhense sob a perspectiva socioambiental e econômica, sobretudo visando garantir o meio de sobrevivência das comunidades que residem no entorno e coibir as práticas abusivas de alguns proprietários da região".

Maria Cutrim e Cabeça me informaram que os fazendeiros do território foram notificados e multados pelo Governo Estadual, mas que mesmo assim continuam desrespeitando a lei. Em Camaputiua ainda não foi realizada a operação para efetivamente retirar as cercas dos campos inundáveis.

Já no município de Matinha, no Território Quilombola de Bom Jesus, também na Baixada Maranhense, a Operação já teve maiores incursões. O Movimento Interestadual de Quebradeiras de Coco Babaçu (MIQCB) encaminhou Ofício ao Núcleo de Direitos Humanos da Defensoria Pública do Estado (DPE) relatando sobre o cercamento dos campos e suas consequências para os quilombolas, como a inacessibilidade aos recursos de pesca e às palmeiras de coco babaçu.

As denúncias dos quilombolas de Bom Jesus foram encaminhadas, além da Defensoria Pública Estadual $^{8}$, para o Ministério Público Estadual, que propuseram conjuntamente uma Ação Civil Pública (ACP) de número 0801866-93.2019.8.10.0097, em face do Estado do Maranhão e dos fazendeiros ali identificados e elencados.

A ACP ainda está em tramitação, e tem como pedidos, dentre outros, os de: determinar a retirada das cercas ilegais dos campos inundáveis e águas públicas da Área de Proteção Ambiental (APA) da Baixada Maranhense, no Município de Matinha/MA, pelo Estado do Maranhão e às expensas de seus proprietários; e determinar que o Estado do Maranhão proceda a fiscalização periódica da prática ilegal de cercamento na área.

Outros pedidos são referentes ao pagamento de dano moral e material aos quilombolas

\footnotetext{
${ }^{8}$ Art. 134. A Defensoria Pública é instituição permanente, essencial à função jurisdicional do Estado, incumbindolhe, como expressão e instrumento do regime democrático, fundamentalmente, a orientação jurídica, a promoção dos direitos humanos e a defesa, em todos os graus, judicial e extrajudicial, dos direitos individuais e coletivos, de forma integral e gratuita, aos necessitados, na forma do inciso LXXIV do art. $5^{\circ}$ desta Constituição Federal (Redação dada pela Emenda Constitucional no 80, de 2014). 
no valor de $\mathrm{R} \$ 500.000,00$ (quinhentos mil reais) cada um a ser pago às famílias atingidas.

A referida ACP ganha relevância pública pois visa à retirada das cercas dos campos públicos inundáveis, tendo como embasamento a ação realizada na "Operação Baixada Livre", que também ocorreu em Camaputiua. É importante vislumbrar o relevante suporte das instituições de justiça em busca de solucionar os conflitos presentes em Camaputiua, com um esteio de esperança de que dias melhores virão.

\section{Considerações finais}

Diante do exposto, observa-se que à medida em que se instalam cercas nos campos inundáveis da Baixada Maranhense, há a privatização do público, pois os campos são reconhecidamente de uso comum.

Ao mesmo tempo, surgem conflitos agrários que põem a vida dos quilombolas em risco, como no caso das cercas eletrificadas. Ademais, as cercas cerceiam o acesso a recursos de uso comum, como o extrativismo de coco babaçu.

Notou-se também a existência de algumas medidas estatais que visam à mitigação de tais conflitos, como no caso da Operação Baixada Livre e de algumas Ações Civis Públicas que foram ajuizadas em outras localidades com existência de conflitos nesses mesmos moldes.

Ademais, cabe ressaltar que os quilombolas de Camaputiua tem feito denúncias da situação perante os órgãos estatais, com a finalidade de pôr fim a conflitos dessa natureza.

Ademais, verificou-se que, mesmo deficitário, o acesso à justiça e às suas instituições tem sido ampliado. O Ministério Público Estadual; o Ministério Público Federal e as Defensorias Públicas do Estado e da União têm prestado apoio aos quilombolas de Camaputiua em algumas demandas, o que tem dado esperança de que tal situação mude na comunidade em questão. 


\section{REFERÊNCIAS}

ALMEIDA, Alfredo Wagner Berno de. O Intransitivo da Transição. O Estado, os conflitos agrários e a violência na Amazônia. In: LÉNA, Philippe e OLIVEIRA, Adélia Engrácia (org.). Amazônia: A fronteira agrícola vinte anos depois. 2 ed. Belém: CEJUP, Museu Paraense Emílio Goeldi, 1992.

ALMEIDA, Alfredo Wagner Berno de. Povos e comunidades tradicionais atingidos por conflitos de terras e atos de violência. In: Conflito no campo Brasil, 2009.

ALMEIDA, Alfredo W. B. de; MOURÃO, Laís. Questões Agrárias no Maranhão Contemporâneo. Manaus: UEA Edições, 2017.

BANNER, Stuart. How the Indians lost their land: Law and power on the frontier. Cambridge: The Belknap Press of Harvard University Press, 2005.

BRASIL. Decreto Federal 24.643 de 10 de julho de 1934. Decreta o Código de Águas. Disponível em: <http://www.planalto.gov.br/ccivil_03/decreto/D24643.htm>. Acesso em: 30 set. 2019.

BRASIL. Decreto no 1.905, de 16 de maio de 1996. Promulga a Convenção sobre Zonas Úmidas de Importância Internacional, especialmente como Habitat de Aves Aquáticas, conhecida como Convenção de Ramsar, de 02 de fevereiro de 1971. Disponível em: <http://www.planalto.gov.br/ccivil_03/decreto/1996/D1905.htm>. Acesso em: 11 fev. 2020.

BRASIL. Lei 9.433 de 08 de janeiro de 1997. Institui a Política Nacional de Recursos Hídricos, cria o Sistema Nacional de Gerenciamento de Recursos Hídricos, regulamenta o inciso XIX do art. 21 da Constituição Federal, e altera o art. $1^{\circ}$ da Lei $n^{\circ} 8.001$, de 13 de março de 1990, que modificou a Lei no 7.990, de 28 de dezembro de 1989. Disponível em: <http://www.planalto.gov.br/ccivil_03/LEIS/L9433.htm>. Acesso em 30 set. 2019.

BRASIL. Lei $\mathbf{n}^{\mathbf{0}} \mathbf{1 2 . 6 5 1}$, de 25 de maio de 2012. Dispõe sobre a proteção da vegetação nativa; altera as Leis n's 6.938, de 31 de agosto de 1981, 9.393, de 19 de dezembro de 1996, e 11.428, de 22 de dezembro de 2006; revoga as Leis $n^{\circ} \mathrm{s} 4.771$, de 15 de setembro de 1965, e 7.754, de 14 de abril de 1989, e a Medida Provisória n 2.166-67, de 24 de agosto de 2001; e dá outras providências. Disponível em: < http://www.planalto.gov.br/ccivil_03/_ato20112014/2012/lei/112651.htm> . Acesso em: 10 fev. 2020.

CARVALHO NETA, Raimunda Nonata Fortes (et al.). Recursos pesqueiros estuarinos em uma ilha da área de proteção ambiental da baixada maranhense. IN: CARVALHO NETA, Raimunda Nonata Fortes (org.). Áreas de Proteção Ambiental no Maranhão: situação atual e estratégias de manejo. São Luís-MA: Editora UEMA, 2015.

CASTRO, Edna. Território, biodiversidade e saberes de populações tradicionais. In: Papers 
do NAEA n. 092. Belém, 1998.

DOURADO, Sheilla Borges. Proteção jurídica dos conhecimentos tradicionais na PanAmazônia: o debate dos debates. Tese (Doutorado). Universidade Federal do Pará. p. 267. 2014.

GIBBS, David; SEYMOUR, Frances. As florestas no relatório especial do IPCC sobre uso da terra: 7 reflexões. Disponível em: <https://wribrasil.org.br/pt/blog/2019/08/florestas-norelatorio-especial-do-ipcc-sobre-uso-do-solo-7-reflexoes>. Acesso em 02 set. 2019.

HAESBAERT, Rogério. O mito da desterritorialização e as "regiões-rede". IN: Anais do V Congresso Brasileiro de Geografia. Curitiba: AGB, 1994.

LEROY, Jean Pierre. Bens comuns e serviços ambientais. In: FASE. Justiça Climática. Revista Trimestral de Debate da FASE Proposta n. 122 -Ano 35 n. 122, ISSN 1982-8950. 2011. p 5- 11.

LOCKE, John. The second treatise of government. Indianapolis: The Library of Liberal Arts, 1952.

MARANHÃO. Constituição do Estado do Maranhão. 1989. Disponível em: <http://www.stc.ma.gov.br/files/2013/03/CONSTITUI\%C3\%87\%C3\%83O-DO-ESTADODO-MARANH\%C3\%83O_atualizada_at\%C3\%A9_emenda69.pdf >. Acesso em 23 abr. 2019.

OST, François. A natureza à margem da lei: a ecologia à prova do direito. Lisboa: Piaget, 1997.

PADILHA, Ednaldo. Entrevista. Entrevistador: Vanessa Cristina Ramos Fonsêca da Silva. Comunidade quilombola Camaputiua, Cajari-MA. 2019, Arquivo. mp3.

PADILHA, Ednaldo. Resistência e fé: o "Cabeça", narrativas de um quilombola. SANTOS, Dorival dos (org.) .2 ed. Rio de Janeiro: Casa 8, 2016.

POLANYI, Karl. A grande transformação: as origens da nossa época. 2.ed. 9. reimpressão. Rio de Janeiro: Elsevier, 2000.

SÁ, Andréa Alves de. Território de uso comum das comunidades tradicionais: uma visão jus socioambiental do criar, fazer e viver dos fundos de pasto da Bahia/Brasil. Tese (Doutorado em Direito das Relações Sociais). Universidade Federal do Paraná. 2010.

SANDRONI, P. Novíssimo dicionário de economia. São Paulo: Best Seller, 1999.

SANTOS, Dorival dos. Identidade Étnica e Territorialidade. Dissertação (Mestrado em Cartografia Social e Política da Amazônia). Universidade Estadual do Maranhão. p. 135. 2015. 
MARANHÃO. Operação Baixada Livre derruba cercas e garante o livre acesso aos campos da Baixada. Disponível em: <https://sedihpop.ma.gov.br/2018/03/21/operacaobaixada-livre-derruba-cercas-e-garante-o-livre-acesso-aos-campos-da-baixada/>. Acesso em: 10 set. 2019.

THOMPSON, E.P. Costumes em comum: estudos sobre a cultura popular tradicional. São Paulo: Companhia das Letras, 1998.

TRIBUNAL DE JUSTIÇA DO ESTADO DO MARANHÃO. Ação Civil Pública. Processo $\mathrm{n}^{\circ}$ 0801866-93.2019.8.10.0097. Vara Única de Matinha. 